\title{
POTENTIAL GEOLOGICAL SIGNIFICATIONS OF CRISIUM BASIN REVEALED BY CE-2 CELMS DATA
}

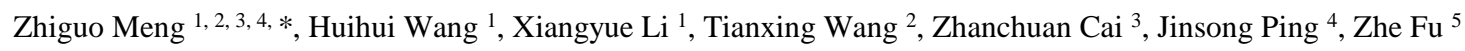 \\ 1. College of Geoexploration Science and Technology, Jilin University, Changchun, 130026, China - mengzg@jlu.edu.cn \\ 2. State Key Laboratory of Remote Sensing Science, Institute of Remote Sensing and Digital Earth, CAS, Beijing, 100101, China - \\ wangtx@radi.ac.cn \\ 3. Lunar and Planetary Science Laboratory, MUST - Partner Laboratory of Key Laboratory of Lunar and Deep Space Exploration, \\ CAS, Macau - zhchcai@126.com \\ 4. Key Laboratory of Lunar and Planetary Exploration, CAS, Beijing, 100012, China - jsping@bao.ac.cn \\ 5. Information Project Evaluation Centre of Beijing, Beijing, 100101, China - fuz@bjeit.gov.cn \\ Tel (86-431)88502362, Fax (86-431)88524544, *mengzg@jlu.edu.cn
}

KEY WORDS: Mare Crisium, Microwave thermal emission, Geological significance, CELMS data, Cold anomaly, Basaltic volcanism

\begin{abstract}
:
Mare Crisium is one of the most prominent multi-ring basins on the nearside of the Moon. In this study, the regolith thermophysical features of Mare Crisium are studied with the CELMS data from CE-2 satellite. Several important results are as follows. Firstly, the current geological interpretation only by optical data is not enough, and a new geological perspective is provided. Secondly, the analysis of the low $T_{B}$ anomaly combined with the $\left(\mathrm{FeO}+\mathrm{TiO}_{2}\right)$ abundance and Rock abundance suggests a special unknown material in shallow layer of the Moon surface. At last, a new basaltic volcanism is presented for Crisium Basin. The study hints the potential significance of the CELMS data in understanding the geological units over the Moon surface.
\end{abstract}

\section{INTRODUCTION}

Crisium $\left(59.1^{\circ} \mathrm{E}, 17.18^{\circ} \mathrm{N}\right)$ is one of the most prominent multiring basins on the nearside of the Moon (Figure 1 (a)). The basin is complex morphologically, suggesting that the basin was subjected to post-formation modification (Blewett et al. 1995; Sliz and Spudis, 2016, Yan et al. 2010). Previous studies show a wide range of ages for the mare basalts here, ranging from 3.75 billion years to perhaps 2.5 billion years (Boyce and Johnson, 1977; Head et al, 1978; Hiesinger et al., 2011). The data from Chang'E (CE) Lunar Microwave Sounder (CELMS) permit a new perspective about the thermophysical features of the mare units in Mare Crisium.

Barsukov et al. (1977) firstly studied the petrochemical and geochemical properties of the regolith and rocks based on the sample data from Luna 24, and the results indicated that the regolith here was monotonous in composition throughout the depth. Later, using the spectral data, Boyce and Johnson (1977) mapped the emplacement of geologic units within Mare Crisium and found three main units in the east central Mare Crisium. Head et al. (1978) divided Mare Crisium into three Groups and an undivided area by studying the regional stratigraphy and geological history in Mare Crisium (Figure 1 (b)). The ages of the three groups were thoroughly studied by Hiesinger et al. (2011) based on LROC WAC images using crater sizefrequency distribution measurement (CSFD). Sliz and Spudis (2016) and Spudis and Sliz (2017) remapped the geological units inner and surrounding of Crisium basin using LRO imagery, Clementine maps of Fe and Ti and LOLA maps, which showed much different from that outlined by Head et al. (1978).

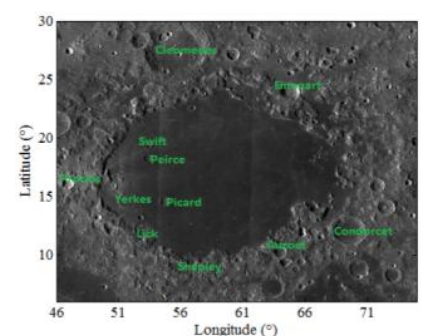

(a)

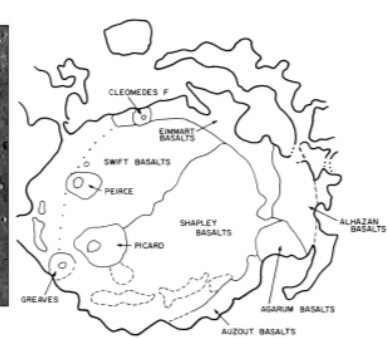

(b)
Figure 1. Geographic map of Mare Crisium (a), and Geological units map (Head et al. 1978) (b).

Note:WAC map was download from https://astrogeology.usgs.gov/search/map/Moon/LRO/LROC_WAC.

The previous work shows the significance of the composition and terrain on the identification of the geological boundaries. However, the aforementioned optical and infrared observations are severely limited by the penetration depth, which is only about several microns (Fang and Fa, 2014; Meng et al., 2017)

In Chinese Chang'E (CE) lunar orbiters, a microwave sounder (CELMS) has successfully obtained the brightness temperatures over the Moon. The data are at four channels including 3.0, 7.8, 19.35 and $37 \mathrm{GHz}$, which are verified to be fairly sensitive to

* Corresponding author 
the regolith thermophysical parameters of the substrate (Zheng et al., 2012; Meng et al., 2016; Meng et al., 2017). Therefore, the CELMS data may present a new perspective about the geological units in Mare Crisium.

In this paper, the CELMS data are introduced to study the microwave thermophysical features of the lunar regolith in Mare Crisium. The data processing is in Section 2. Section 3 analyzes the spatial and temporal changes of the brightness temperature $\left(T_{B}\right)$ in Mare Crisium. Section 4 analyzes the influence of different factors on $\mathrm{n} T_{B}$. Section 5 provides geological significance revealed by CELMS data. Section 6 is conclusions.

\section{DATA PROCESSING}

The CELMS data used were from the CE-2 lunar orbiter, and the observation time was from October of 2010 to May of 2011. To avoid validation bias, only ascending-orbit data have been introduced in to the data analysis. In the original CELMS dataset, the observation angle was $0^{\circ}$ and the temperature resolution was about $0.5 \mathrm{~K}$.

\section{1 $T_{B}$ maps generation}

The local time, surface temperature, plays an important role on the observed CELMS data. To decrease the surface temperature impact, firstly, the time angle was introduced to attribute the CELMS data into specific observation time interval. After thoroughly contrastive analysis, the time angles from $-15^{\circ}$ to $0^{\circ}$ and from $150^{\circ}$ to $165^{\circ}$ are selected, which have enough samples to generate the brightness temperature $\left(T_{B}\right)$ maps of Mare Crisium. The corresponding observation time was from 11 o'clock to 12 o'clock which can represent the noontime and from 22 o'clock to 23 o'clock representing midnight, respectively. Then, the interpolation method is applied to generated $T_{B}$ maps at noon and at midnight. The spatial resolution is about $0.25^{\circ} \times 0.25^{\circ}$. The noon readings have the highest surface temperatures and those at midnight have the lowest. They represent the two extreme phases of the Moon surface, which are the most appropriate time to study the thermal behaviors of the lunar regolith with CELMS data (Ulaby et al., 1981; Meng et al., 2017)

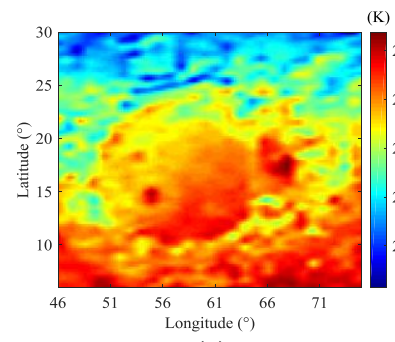

(a)

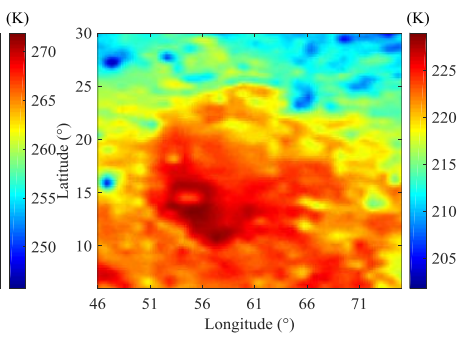

(b)
Figure 2. $T_{B}$ at $37 \mathrm{GHz}$ at noon (a) and at midnight(b).

\section{$2.2 \mathrm{n} T_{B}$ maps generation}

Figure 2 shows good thermophysical features of Mare Crisium, where the $T_{B}$ in the Basin floor is higher than its vicinity. However, the $T_{B}$ obviously changes with the latitude. Considered Considering the declining of the surface temperature with the increasing latitude (Racca, 1995; Meng et al., 2014), this $T_{B}$ changes is resulted from the surface temperature, but not the thermophysical parameters of the lunar regolith. The $37 \mathrm{GHz} T_{B}$ variation with latitude is up to $25 \mathrm{~K}$ at noon and $15 \mathrm{~K}$ at midnight, which is much larger than that from the thermophysical parameters of the lunar regolith. To eliminate the impact of the surface temperature, the standard $T_{B}$ is introduced, which is defined by using a series of $T_{B}$ locating in different latitude. They have similar observation conditions, including the components, surface slope, and rock abundance. Once the standard $T_{B}$ is identified, it can be employed to generate the $\mathrm{n} T_{B}$ by dividing the observed $T_{B}$ by the standard $T_{B}$ of the corresponding latitude, which is expected to eliminate the variation of the observed $T_{B}$ with the latitude (Figures 3 and 4).

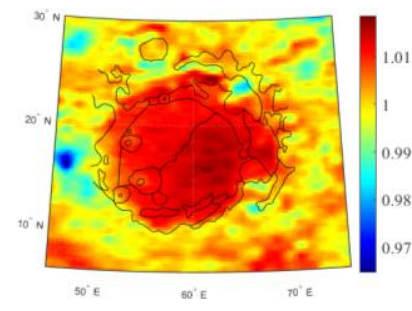

(a) $3.0 \mathrm{GHz}$

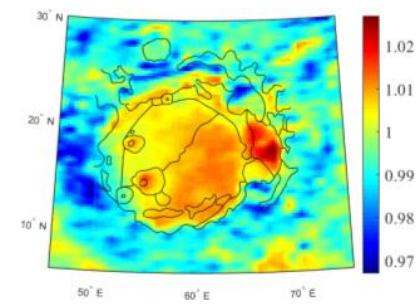

(c) $19.35 \mathrm{GHz}$

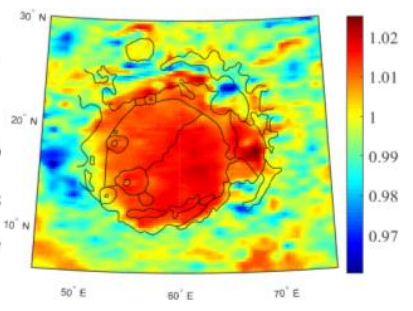

(b) $7.8 \mathrm{GHz}$

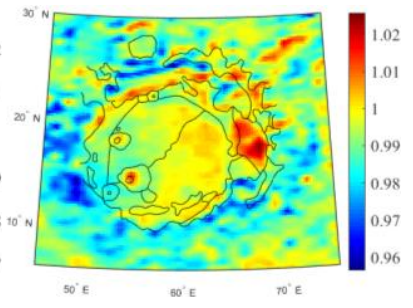

(d) $37 \mathrm{GHz}$
Figure 3. $\mathrm{n} T_{B}$ at Noon of Mare Crisium

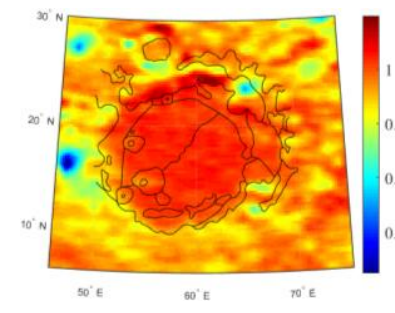

(a) $3.0 \mathrm{GHz}$

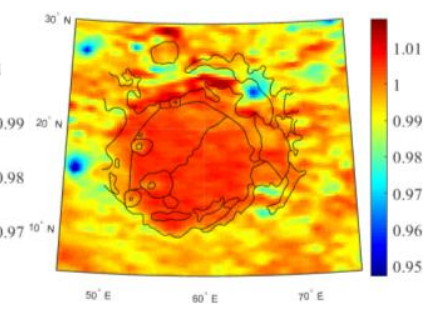

(b) $7.8 \mathrm{GHz}$

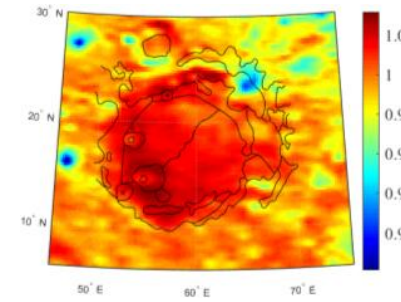

(c) $19.35 \mathrm{GHz}$

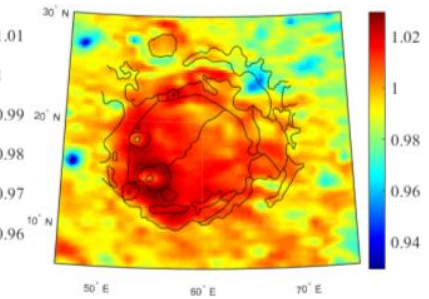

(d) $37 \mathrm{GHz}$
Figure 4. $\mathrm{n} T_{B}$ at night of Mare Crisium

Figures 3 and 4 present that the change of the $T_{B}$ with latitude efficiently removed. The Peirce and Picard craters in the Basin floor, and the Proclus, Eimmart, Condorcet, and Auzout craters in the surroundings can be easily identified with relatively lower $\mathrm{n} T_{B}$ values compared to their vicinity. Moreover, the $\mathrm{n} T_{B}$ in the northern walls of Cleomedes, Eimmart, and Condorcet craters is much higher than that in their southern walls, coinciding with the $T_{B}$ behaviors in Tycho crater (Meng et al., 2017). This also hints the rationality of the generated $\mathrm{n} T_{B}$ maps. 


\section{RESULTS}

Figures 3 and 4 indicate a new perspective about the mare basalts in Crisium Basin. To better understand the thermophysical parameters of the regolith in different mare units, the geological boundaries interpreted by Head et al. (1978) are vectorized and overlaid on the generated $\mathrm{n} T_{B}$ maps.

\subsection{Daytime Behaviors}

Figure 3 is the $\mathrm{n} T_{B}$ at noon, where the Moon is in the highest surface temperature of a whole day. In the Basin floor, the highest $\mathrm{n} T_{B}$ occurs in the eastern part (Alhazan Basalts) and southeastern part (Shapley Basalts). With the increasing frequency, the area of Alhazan basalts unit keeps constant, while the area of the Shapley Basalts unit becomes smaller. Additionally, the $\mathrm{n} T_{B}$ in Shapley Basalts unit is similar to that in Alhazan Basalts unit at $3.0 \mathrm{GHz}$, but it is much lower than the latter at the other three channels.

Moreover, the Swift Basalts unit in the northwestern Basin floor is apparently lower than that in the Shapley Basalts unit. The area of the Swift Basalts unit with relatively lower $\mathrm{n} T_{B}$ increases greatly with the increasing frequencies. Also, there are two small patches within Shapley Basalts unit belonging to Swift Basalts. But the $\mathrm{n} T_{B}$ in the two patches is similar to that in Shapley Basalts unit at 3.0 and $7.8 \mathrm{GHz}$. Only at 19.35 and 37 $\mathrm{GHz}$, the $\mathrm{n} T_{B}$ in the two patches is similar to that in Swift basalts unit, while their distributions are clearly different from that indicated by the optical data used by Head et al. (1978).

Additionally, the $\mathrm{n} T_{B}$ in Peirce, Picard, Greaves, and Cleomedes F craters is similar to their vicinity at 3.0 and $7.8 \mathrm{GHz}$. But at 19.35 and $37 \mathrm{GHz}$, the $\mathrm{n} T_{B}$ in Peirce, Picard, and Cleomedes $\mathrm{F}$ craters is obviously lower than their vicinity, while it is also similar to the vicinity in Greaves crater.

The mare basalt in Auzout Basalts unit is similar to that in Alhazan Basalts unit, but the $\mathrm{n} T_{B}$ at every channel is apparently lower than that in the latter. This hints that they should not be attributed to the same basalts group.

Agarum and Eimmart Basalts units belong to Group II B. The $\mathrm{n} T_{B}$ here is higher than the nearby highlands but similar to the nearby Swift Basalts unit.

The $\mathrm{n} T_{B}$ behaviors in the undivided group are rather complex. Only in the regions near Peirce and Eimmart craters, they show higher $\mathrm{n} T_{B}$ values at the four channels, while the area with high values decreases soundly with the increasing frequency.

The $\mathrm{n} T_{B}$ in the nearby highlands is apparently lower than that in the Basin floor. Here, two interesting phenomena should be paid severe attention. Firstly, there are abundant regions with relatively higher $\mathrm{n} T_{B}$ at $3.0 \mathrm{GHz}$, while they become as low as their outer vicinity. Secondly, the lowest $\mathrm{n} T_{B}$ occurs in Proclus crater, and the $\mathrm{n} T_{B}$ nearby Proclus crater is also lower than that in other regions.

\subsection{Nighttime behaviors}

Figure 4 is the $\mathrm{n} T_{B}$ at midnight, where the Moon is in the lowest surface temperature of a whole day.

Compared to Figure 3, Figure 4 presents an almost totally different view about Mare Crisium. Firstly, the $n T_{B}$ in the Basin floor is also apparently higher than the vicinity, but the difference in $\mathrm{n} T_{B}$ values between the Basin floor and its vicinity is decreased. Also, the differences between four interpreted geological units are disappeared. Secondly, the regions in the western Basin floor shows relatively higher $\mathrm{n} T_{B}$ except Picard crater and its near vicinity at 19.35 and $37 \mathrm{GHz}$.

Interestingly, the $\mathrm{n} T_{B}$ in Proclus crater is still lowest in the whole study area. Apparently, the relatively lower $\mathrm{n} T_{B}$ also occurs in Eimmart, crater in $\left(27.5^{\circ} \mathrm{N}, 46.9^{\circ} \mathrm{E}\right)$, and crater in $\left(12^{\circ} \mathrm{N}, 65.7^{\circ} \mathrm{E}\right)$, which also present considerably low $\mathrm{n} T_{B}$ at noon. Theoretically, the low $T_{B}$ at daytime should be high at night (Ulaby et al., 1981; Wang et al., 2010; Meng et al., 2016). The lowest $\mathrm{n} T_{B}$ in these craters can hardly be interpreted by the theoretical model, which should be paid more attention in the future.

\section{GENESIS ANALYSIS}

To further understand the thermophysical features of the mare basalts in Crisium Basin, the $\left(\mathrm{FeO}+\mathrm{TiO}_{2}\right)(\mathrm{FTA})$ derived from Clementine UV-VIS data, surface slope derived from LOLA data and rock abundance (RA) derived from LRO Diviner data are introduced in this study (Figure 5).

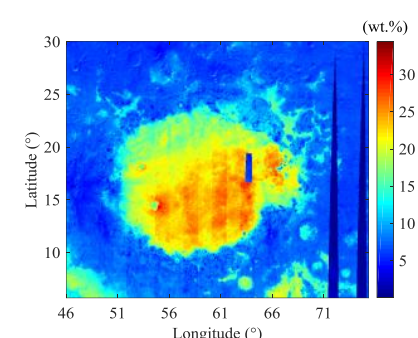

(a)

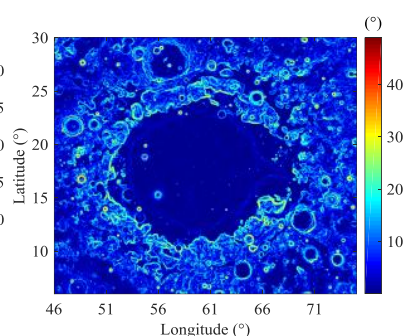

(b)

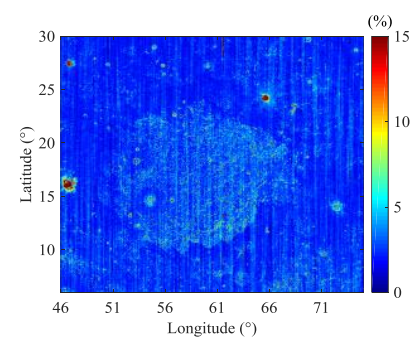

(c)

Figure 5. FTA (a), surface slope (b), and rock abundance (c) of Mare Crisium.

\subsection{FTA influence}

The FTA in Mare Crisium was estimated with the Lucey model (Lucey et al., 2000) using the Clementine UV-VIS data. Figure 5 (a) shows the spatial distribution of FTA in Mare Crisium, which is supposed to be one of the most important factors of $T_{B}$ in local region (Chan et al. 2010; Meng et al 2016). The average FTA of the basin floor is about 20.8 wt.\%, which is much higher than that at the surroundings. And the corresponding $\mathrm{n} T_{B}$ in the basin floor is also apparently higher than the vicinity at noon. Moreover, in the basin floor, two geological units were interpreted mainly based on the FTA (Head et al., 1978). The mean FTA is about 22.8 wt.\% in Shapley Basalts unit and about 19.2 wt.\% in Swift Basalts unit, while the average $T_{B}$ is $234.5 \mathrm{~K}$ and $233.7 \mathrm{~K}$, respectively, at $3.0 \mathrm{GHz}$ at noon. Such relationship agrees well with the simulation results by Jin et al. 
(2003), Wang et al. (2010), and Meng et al. (2016). This again verifies the rationality of the generated $\mathrm{n} T_{B}$ maps.

However, the $T_{B}$ difference between the two basalts units in the Basin floor is much lower than the simulation results using the theoretical model (Jin et al., 2003; Wang et al., 2010). What's more, if we sampled the special regions in the two basalts units, the corresponding mean $T_{B}$ is about $236.4 \mathrm{~K}$ and $232.6 \mathrm{~K}$.

This doesn't show the slight difference between the two geological units in $T_{B}$, but hints the irrationality of the geological boundaries interpreted only using optical data.

Moreover, the FTA in Proclus crater, Eimmart crater, crater in $\left(27.5^{\circ} \mathrm{N}, 46.9^{\circ} \mathrm{E}\right)$, and crater in $\left(12^{\circ} \mathrm{N}, 65.7^{\circ} \mathrm{E}\right)$ is lowest, which may provide some hints about the low $\mathrm{n} T_{B}$ anomaly here.

\subsection{Topography influence}

The surface slope was calculated with the LRO LOLA data using the Horn algorithm (Tang et al., 2005), which is estimated as essential parameters for the $T_{B}$ in the crater wall facing the sunshine (Meng et al., 2014; Hu et al., 2014). Figure 5 (b) is the surface slope of Crisium Basin. Figure 5 (b) indicates the similar surface slope in the Basin floor, and the huge fluctuation within the craters rims. Combined with Figure 3, the high $\mathrm{n} T_{B}$ in the northern inner walls of Cleomedes crater and Mare Crisium and the relatively low $\mathrm{n} T_{B}$ in the southern inner wall of Clemedes crater and the northern outer wall of Mare Crisium are likely resulted from the surface slope.

However, in other regions, the $\mathrm{n} T_{B}$ distribution has nothing to do with the surface slope here, hinting that the surface slope nearly has no influence on the observed CELMS data.

\subsection{RA influence}

RA is always thought as an important role for the cold anomaly (Chan et al., 2010; Gong and Jin, 2012; Bandfield et al., 2014), which were downloaded from JMARS software (Christensen et al. 2009).

Figure 5 (c) is the rock abundance of the Mare Crisium. The RA values in Proclus crater, Eimmart crater, crater in $\left(27.5^{\circ} \mathrm{N}\right.$, $\left.46.9^{\circ} \mathrm{E}\right)$, and crater in $\left(12^{\circ} \mathrm{N}, 65.7^{\circ} \mathrm{E}\right)$ are all fairly high, which are nearly the highest in the whole study area. The strong correlation implies that the RA is likely the causes for low $T_{B}$ anomaly.

Gong and Jin (2012) presented that the $T_{B}$ is relatively higher at noon but relatively lower at night in the regions with high RA values than their vicinity. But, our observation indicates that the regions with high RA values have low $T_{B}$ both at noon and at night.

Interestingly, the RA in Basin floor is also much higher than the vicinity. Moreover, there still exist abundant small craters with obviously higher RA values than their nearby regions, including Peirce, Picard, and Yerkes craters. However, the $\mathrm{n} T_{B}$ behaviors are completely different from that in the aforementioned four craters.

Therefore, the relationship between the RA and the low $T_{B}$ anomaly should be critically treated.

Fortunately, the RA values are nearly evenly distribution in Crisium Basin floor. Therefore, the influence of the RA on the $\mathrm{n} T_{B}$ can be omitted when discussing the geological features of the Basin floor.

\section{GEOLOGICAL SIFNIFICANCE}

Compared to the optical and thermal infrared results, the CELMS data presented a new geological perspective about Mare Crisium.

\subsection{Geological Applications}

Figure 3 presents several different views about the basalts units in Mare Crisium, which are indicated by the $\mathrm{n} T_{B}$ distributions with the frequency. Two issues should be mentioned at first. One is the strong relationship between the FTA and the $\mathrm{n} T_{B}$ (Meng et al., 2016; Zanetti et al., 2017), which is also verified in Section 4.1. The other is the penetration capabilities of the used microwave, which can be up to ten to twenty times of the wavelength over the Moon surface (Campbell et al., 2008).

Thus, the $\mathrm{n} T_{B}$ in the Basin floor indirectly provides the clues about the lunar regolith in the substrate. In the depth penetrated by $3.0 \mathrm{GHz}$ microwave, the area of the region with high $\mathrm{n} T_{B}$ is much larger than that identified by Head et al. (1978). In the shallower layer penetrated by $37 \mathrm{GHz}$ microwave, the $\mathrm{n} T_{B}$ occurs only in the eastern Basin floor. That is, Shapley Basalts units should be widely distributed in Crisium Basin in depth, about $2 \mathrm{~m}$. And the Swift Basalts unit largely occurs in the shallow layer.

Moreover, there exists one small patch near Fahrenheit crater $\left(13.1^{\circ} \mathrm{N}, 61.7^{\circ} \mathrm{E}\right)$ with low $\mathrm{n} T_{B}$, which is only apparent at 37 $\mathrm{GHz}$ map and is in the north part compared to the interpreted Swift Basalts unit here. This presents that the thickness of the patch is larger than $16.2 \mathrm{~cm}$ but no more than $62 \mathrm{~cm}$.

To Swift Basalts unit, the $\mathrm{n} T_{B}$ here is not apparently different from that in Auzout Baslats, Eimmart Basalts, and Undivided units, meaning the homogeneity of the regolith thermophysical parameters in the four units.

Additionally, in Peirce and Picard craters, the $\mathrm{n} T_{B}$ is similar to that in Swift Basalts unit at 3.0, 7.8, and $19.35 \mathrm{GHz}$, while the $\mathrm{n} T_{B}$ in the central parts is similar to that in Shapley Basalts. This is important to further understand the mare basalts in Crisium Basin. Combined with the previous mentioned change of the Shapley Basalts units with depth, the $\mathrm{n} T_{B}$ behaviors in Peirce and Picard craters likely indicate that the Shapley Basalts unit should be distributed in the whole Basin floor in depth.

\subsection{Low $T_{B}$ anomaly}

The low $T_{B}$ anomaly in Proclus crater, Eimmart crater, crater in $\left(27.5^{\circ} \mathrm{N}, 46.9^{\circ} \mathrm{E}\right)$, and crater in $\left(12^{\circ} \mathrm{N}, 65.7^{\circ} \mathrm{E}\right)$ shows a strong correlation with the rock abundance, but the simulation results by Gong and Jin (2012) and the RA values in the Basin floor seemingly don't support the correlation.

Here, we mentioned that the lowest FTA also occurs in the four craters. That is, the regolith components should also play certain role on the low $T_{B}$ anomaly. Among the four craters, Eimmart crater has a distinct view compared to the other three craters. Interestingly, the high resolution WAC image (Figure 6.) indicates that there exists a small Copernicus crater in the eastern rim. Combined the low $\mathrm{n} T_{B}$ surrounding the regions centered at the four mentioned craters, it implies that there is 
likely a special material in shallow layer of the Moon surface, which was excavated by the four craters. Then this material is spread out around the crater.

Moreover, the craters in different sizes are widely distributed in the study area, and the low $\mathrm{n} T_{B}$ only occurs in the aforementioned four craters. This indicates that the distribution of the special material in depth is not even.

This is only a hypothesis for the formation of the low $\mathrm{n} T_{B}$ anomaly, which should be further studied with more sources of data and even the in-situ measurements. The related discoveries will be helpful to further understand the lunar crust.

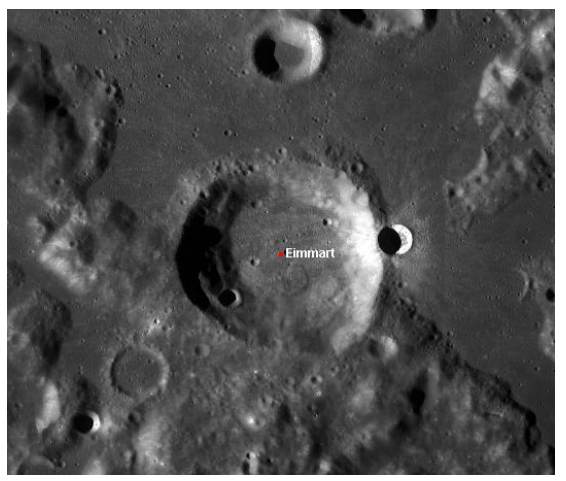

Figure 6. WAC map of Eimmart Crater

\subsection{Basaltic Volcanism}

The previous analysis provides some essential clues about the basaltic volcanism in Mare Crisium.

One important $\mathrm{n} T_{B}$ behavior is obscured in the previous discussions which is located in Alhazan Basalts unit. Here, it has the highest FTA values and the highest $\mathrm{n} T_{B}$ values at noon. Moreover, abundant uplifts and depressions exist in this unit (Figure 7.). This hints that this is likely the origination area of the lava for Mare Crisium (Yan et al. 2012).

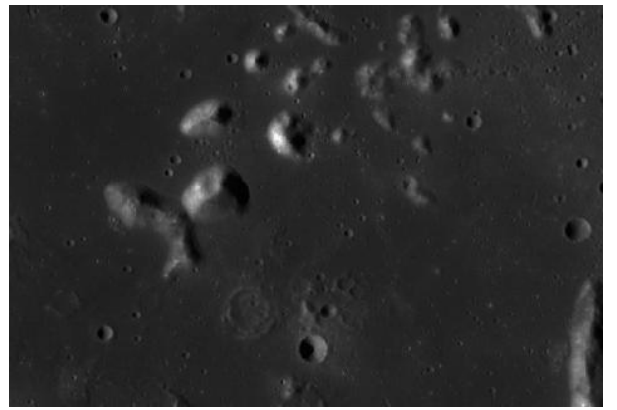

Figure 7. WAC map of part of Alhazan Basalts unit

If so, the mare volcanism can be reconstructed as follows.

Crisium Basin may have the mare basalts in different era. But in the shallow layer penetrated by the $3.0 \mathrm{GHz}$ microwave, only the Shapley Basalts unit exists. This is directly proved by the $\mathrm{n} T_{B}$ at 3.0 and $7.8 \mathrm{GHz}$.

Thereafter, the mare basalts in the western part are heavily impacted by the ejecta from an unknown source. This can be consolidated by the $\mathrm{n} T_{B}$ at 19.35 and $37 \mathrm{GHz}$ at noon. The region with relatively lower $\mathrm{n} T_{B}$ only occurs in a small patch of the western Basin floor, while the area becomes much larger at
$37 \mathrm{GHz}$ than that at $19.35 \mathrm{GHz}$. Also, the distribution of the regions with low $\mathrm{n} T_{B}$ hints that the ejecta is from the northwest place.

At last, the formation of the Peirce and Picard craters excavated the Shapley Basalts with high FTA.

Generally, the CELMS data provide a distinct different view about the mare basalts in Crisium Basin.

\section{CONCLUSION}

In this study, the regolith thermophysical features of Mare Crisium are studied with the CELMS data from CE-2 satellite. Several important results are presented as follows.

1. Shapley Basalts units should be widely distributed in Crisium Basin in depth, about $2 \mathrm{~m}$. And the Swift Basalts unit largely occurs in the shallow layer.

2. To Swift Basalts unit, the $\mathrm{n} T_{B}$ here is not apparently different from that in Auzout Baslats, Eimmart Basalts, and Undivided units, meaning the homogeneity of the regolith thermophysical parameters in the four units.

3. The low $T_{B}$ anomaly occurs in Proclus crater, Eimmart crater, crater in $\left(27.5^{\circ} \mathrm{N}, 46.9^{\circ} \mathrm{E}\right)$, and crater in $\left(12^{\circ} \mathrm{N}, 65.7^{\circ} \mathrm{E}\right)$. The preliminary result is that there likely exists a special material in shallow layer of the Moon surface, which was excavated by the four craters. Then this material is spread out around the crater.

4. The change of the $\mathrm{n} T_{B}$ with frequency presents that Alhazan Basalts unit is likely the origination area of the lava for Mare Crisium; only the Shapley Basalts unit filled Crisium Basin, and the contamination of the ejecta materials changed the superficial layer of the mare basalt in the western Basin floor.

Generally, the study presents the potential significances of the CE-2 CELMS data in the lunar volcanism study. However, the formation of low $T_{B}$ anomaly revealed by CELMS data need to be verified in the future.

\section{ACKNOWLEDGEMENTS}

This work is supported by the National Natural Science Foundation of China (No. 41371332, 41590851), the Open Fund of State Key Laboratory of Remote Sensing Science (Grant No. OFSLRSS201706), and opening fund of Lunar and Planetary Science Laboratory, MUST - Partner Laboratory of Key Laboratory of Lunar and Deep Space Exploration, CAS (Macau FDCT grant No. 039/2013/A2). The Clementine UVVIS data are downloaded from http://webgis.wr.usgs.gov /pigwad/down. The LOLA data are downloaded from http://pdsgeosciences.wustl.edu/lro. We are grateful for allowing us to use their data!

\section{REFERENCES}

Bandfield, J.L., Song, E., Hayne, P.O., Brand, B.D., and Ghent, R.R., 2014. Lunar cold spots: Granular flow features and extensive insulating materials surrounding young craters. Icarus, 231(4), pp. 221-231.

Barsukov, V.L., Tarasov, L.S., Dmitriev, L.V., Kolesov, G.M., Shevaleevsky, I.D., and Garanin, A.V., 1977. The geochemical and petrochemical features of regolith and rocks from Mare 
Crisium (preliminary data). Proc. Lunar Sci. Conf. 8th, pp. 3319-3332.

Blewett, D.T., Hawke, B.R., and Lucey, P.G., 1995. A spectral survey of the Crisium basin region of the Moon. Geophys. Res. Lett., 22(22), pp. 3059-3062.

Boyce, J.M., and Johnson, D.A., 1977. Age of flow units in Mare Crisium based on crater density. Proc. Lunar Sci. Conf. 8th, pp. 3495-3502

Campbell, B.A., Carter, L.M., Hawke, B.R., Campbell, D.B., and Ghent, R.R., 2008. Volcanic and impact deposits of the moon's Aristarchus plateau: a new view from earth-based radar images. Geology, 36(2), pp. 135-138

Chan, K.L., Kang, T.T., Kong B, and Zheng, Y.C., 2010. Lunar regolith thermal behavior revealed by Chang'E-1 microwave brightness temperature data. Earth \& Planetary Science Letters, 295(1-2), pp. 287-291.

Christensen, P.R., Engle, E., Anwar, S., Dickenshied, S., Noss, D., Gorelick, N., and Weiss-Malik, M.,2009. JMARS - A Planetary http://adsabs.harvard.edu/abs/2009AGUFMIN22A..06C

Fang, T., and Fa, W.Z., 2014. High frequency thermal emission from the lunar surface and near surface temperature of the Moon from Chang'E-2 microwave radiometer. Icarus, 232, pp. 34-53.

Gong, X.H., and Jin, Y.Q., 2012. Diurnal change of thermal emission with "hot spots" and "cold spots" of fresh lunar craters observed by Chinese Chang'E-1. Sci. China. Inform. Sci., 42(8), pp. 923-935.

Head, III, J.W., Adams, J.B., Mccord, T.B., Pieters, C., and Zisk, S., 1978. Regional stratigraphy and geologic history of Mare Crisium. Geophys. Res. Lett., 5(4), pp. 313-316.

Hiesinger, H., Van der Bogert, C.H., Reiss, D., and Rpbinson, M.S., 2011. Absolute model ages of basalts in Mare Crisium. European Planetary Science Congress. 1095.

Hu, G.P., Chen, K., Huang, Q., Guo, W., Li, Q., Gui, L., and Cheng, Y., 2014. Brightness Temperature Calculation of Lunar Crater: Interpretation of Topographic Effect on Microwave Data from Chang'E. Geoscience \& Remote Sensing, 52(8), pp. 4499 4510 .

Jin, Y.Q., Yan, F.H., Liang, and Z.C., 2003. Simulation for remote sensing of the lunar soil and rock by using multichannels microwave radiometers. Chin. J.Radio Sci., 18(5), pp. 477-486.

Lucey, P.G., Blewett, D.T., and Jolliff, B.L., 2000. Lunar iron and titanium abundance algorithms based on final processing of Celmentine ultraviolet-visible images. J. Geophys. Res.-Planet., 105(E8), pp. 20297-20306.

Meng, Z.G., Xu, Y., Cai, Z.C., Chen, S.B., Lian, Y., and Huang, H., 2014. Influence of Lunar Topography on Simulated Surface Temperature. Adv. Space. Res., 54(10), pp. 2131-2139.
Meng, Z.G., Zhang, J.D., Tang, Z.S., Ping, J.S., and Cai, Z.C., 2016. Microwave thermal emission features of Mare Orientale revealed by CELMS data. IGARSS, pp. 5402-5405.

Meng. Z.G., Zhao, R., Cai, Z.C. Ping, J.S., Tang, Z.S., and Chen, S., 2017. Microwave Thermal Emission at Tycho Area and Its Geological Significance. IEEE J-STARS, 10(6), pp. 2984-2990.

Racca, G. D., 1995. Moon surface thermal characteristics for Moon orbiting spacecraft thermal analysis. Planet. Space Sci., 43(6), pp. 835-842.

Sliz, M.U., and Spudis, P.D., 2016. New geologic map of the lunar Crisium Basin. Proc. Lunar Sci. Conf., 47.

Spudis, P.D., and Sliz, M.U., 2017. Impact melt of the lunar Crisium multiring basin. Geophys. Res. Lett., 44(3), pp. 12601265 .

Tang, A.G., Liu, X.J., and Yan, G.N., 2005. Principle and Application of theDigital Elevation Model and Geological Analysis. Science Press, Beijing.

Ulaby, F.T., Moore, R.K., Fung, A., and Feng, J.C., 1981. Microwave remote sensing. MA, USA: Addison-Wesley, pp. 51-61.

Wang, S.J., Xiong-Yao, L., Tang, H., and Yang, A.L., 2010. Lunar surface environment and properties of lunar soil. Geochimica, 39(1), pp. 73-81.

Yan, J.G., Goossens, S., Matsumoto, K., Ping, J.S., Harada, Y., Iwata, T., Namiki, N., Li, F., Tang, G.S., Cao, J.F., Hanada, H., and Kawano, N., 2012. CEGM02: An improved lunar gravity model using Chang'E-1 orbital tracking data. Plane. Space Sci., 62(1), pp. 1-9.

Yan, J.G., Ping, J.S., Li, F., Cao, J.F., Huang, Q., and Fung, L.H., 2010. Chang'E-1 precision orbit determination and lunar gravity field solution. Adv. Space. Res., 46(1), pp. 50-57.

Zanetti, M., Stadermann, A., Jolliff, B., Hiesinger, H., Van der Bogert, C.H., and Plescia, J., 2017. Evidence for self-secondary cratering of Copernican-age continuous ejecta deposits on the Moon. Icarus, 298, pp. 64-77.

Zheng, Y.C., Tsang, K.T., Chan, K.L., Zou, Y.L., and Zhang, F., 2012. First microwave map of the Moon with Chang'E-1 data: The role of local time in global imaging. Icarus, 219(1), pp. 194-210. 